\title{
Nanoscale Coloristic Pigments: Upper Limits on Releases from Pigmented Plastic during Environmental Aging, In Food Contact, and by Leaching
}

Neubauer, Nicole; Scifo, Lorette; Navratilova, Jana; Gondikas, Andreas; Mackevica, Aiga; Borschneck, Daniel; Chaurand, Perrine; Vidal, Vladimir; Rose, Jerome; von der Kammer, Frank

Total number of authors:

11

Published in:

Environmental Science and Technology

Link to article, DOI:

10.1021/acs.est.7b02578

Publication date:

2017

Document Version

Publisher's PDF, also known as Version of record

Link back to DTU Orbit

Citation (APA):

Neubauer, N., Scifo, L., Navratilova, J., Gondikas, A., Mackevica, A., Borschneck, D., Chaurand, P., Vidal, V., Rose, J., von der Kammer, F., \& Wohlleben, W. (2017). Nanoscale Coloristic Pigments: Upper Limits on Releases from Pigmented Plastic during Environmental Aging, In Food Contact, and by Leaching. Environmental Science and Technology, 51(20), 11669-11680. https://doi.org/10.1021/acs.est.7b02578

\section{General rights}

Copyright and moral rights for the publications made accessible in the public portal are retained by the authors and/or other copyright owners and it is a condition of accessing publications that users recognise and abide by the legal requirements associated with these rights.

- Users may download and print one copy of any publication from the public portal for the purpose of private study or research.

- You may not further distribute the material or use it for any profit-making activity or commercial gain

- You may freely distribute the URL identifying the publication in the public portal 


\title{
Nanoscale Coloristic Pigments: Upper Limits on Releases from Pigmented Plastic during Environmental Aging, In Food Contact, and by Leaching
}

\author{
Nicole Neubauer, ${ }^{\dagger}$ Lorette Scifo, Jana Navratilova, ${ }^{\S, \perp}$ Andreas Gondikas, ${ }^{\S}$ Aiga Mackevica, ${ }^{\ddagger}$
} Daniel Borschneck, ${ }^{\ddagger}$ Perrine Chaurand, ${ }^{\ddagger}$ Vladimir Vidal, ${ }^{\ddagger}$ Jerome Rose, ${ }^{\ddagger}$ Frank von der Kammer, ${ }^{\S}$ and Wendel Wohlleben $* \dagger+(0$

\author{
${ }^{\dagger}$ BASF SE, Material Physics, GMC/R, Carl-Bosch-Strasse 38, 67056 Ludwigshafen, Germany \\ ${ }^{*}$ CEREGE UR 34 Aix Marseille University - CNRS - IRD, 13545, Marseille, Aix-en-Provence France \\ ${ }^{\S}$ University of Vienna, Department of Environmental Geosciences, 1090 Vienna, Austria \\ ${ }^{\|}$Technical University of Denmark, Department of Environmental Engineering, 2800 Kgs. Lyngby, Denmark
}

\author{
Supporting Information
}

\begin{abstract}
The life cycle of nanoscale pigments in plastics may cause environmental or human exposure by various release scenarios. We investigated spontaneous and induced release with mechanical stress during/after simulated sunlight and rain degradation of polyethylene (PE) with organic and inorganic pigments. Additionally, primary leaching in food contact and secondary leaching from nanocomposite fragments with an increased surface into environmental media was examined. Standardized protocols/methods for release sampling, detection, and characterization of release rate and form were applied: Transformation of the bulk material was

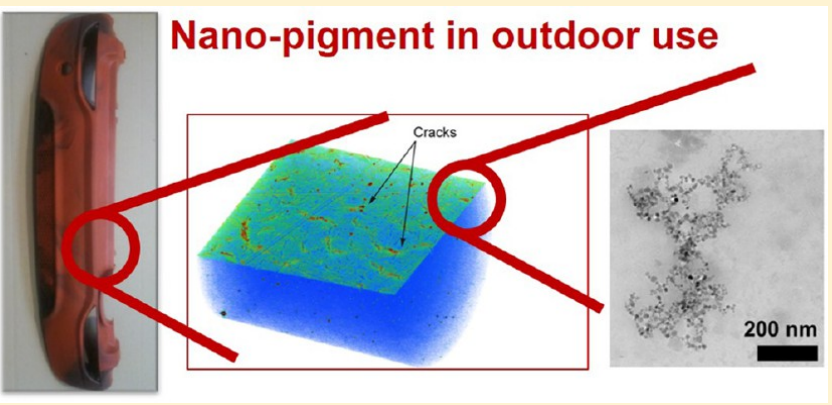
analyzed by Scanning Electron Microscopy (SEM), X-raytomography and Fourier-Transform Infrared spectroscopy (FTIR); releases were quantified by Inductively Coupled Plasma Mass Spectrometry (ICP-MS), single-particle-ICP-MS (sp-ICP-MS), Transmission Electron Microscopy (TEM), Analytical Ultracentrifugation (AUC), and UV/Vis spectroscopy. In all scenarios, the detectable particulate releases were attributed primarily to contaminations from handling and machining of the plastics, and were not identified with the pigments, although the contamination of $4 \mathrm{mg} / \mathrm{kg}(\mathrm{Fe})$ was dwarfed by the intentional content of $5800 \mathrm{mg} / \mathrm{kg}\left(\mathrm{Fe}\right.$ as $\mathrm{Fe}_{2} \mathrm{O}_{3}$ pigment). We observed modulations (which were at least partially preventable by UV stabilizers) when comparing as-produced and aged nanocomposites, but no significant increase of releases. Release of pigments was negligible within the experimental error for all investigated scenarios, with upper limits of $10 \mathrm{mg} / \mathrm{m}^{2}$ or 1600 particles $/ \mathrm{mL}$. This is the first holistic confirmation that pigment nanomaterials remain strongly contained in a plastic that has low diffusion and high persistence such as the polyolefin High Density Polyethylene (HDPE).
\end{abstract}

\section{INTRODUCTION}

As nanomaterial containing products may undergo structural and chemical transformations during their entire life cycle including production, use, and disposal, it is highly desirable to include their whole life cycle in safety assessment. Recently, both the release from nanocomposites and the risk assessment during their life cycle were described in detail in several review papers. $^{1-3}$ Main pathways of matrix degradation and decomposition, which mainly influence release behavior of nanocomposites, are described as aging by UV, hydrolysis, mechanical processing and thermal treatment. ${ }^{4}$ Released fragments are mainly dominated by matrix fragments with enclosed or protruding nanofillers, ${ }^{5-8}$ but free nanofillers are occasionally observed. $^{9-11}$ Toxicological studies on such fragments released during life cycle simulations from nano- composites, based on different matrices such as Particulate Organic Matter (POM), epoxy, concrete, or paint, showed that the toxicity of released fragments is matrix-dependent as well. $^{12-17}$ Thus, they exhibit different biological effects compared to the pristine form of the nanofillers, and therefore allow a more realistic estimation of potential risks.

Coloristic pigments are used ubiquitously to give color to plastics, coatings and paints. ${ }^{18-20}$ Whereas dyes are molecularly dissolved in the matrix, pigments are insoluble and are dispersed as particles. Dyes provide brilliant colors, but pigment

Received: May 19, 2017

Revised: $\quad$ August 23, 2017

Accepted: August 25, 2017

Published: October 8, 2017 


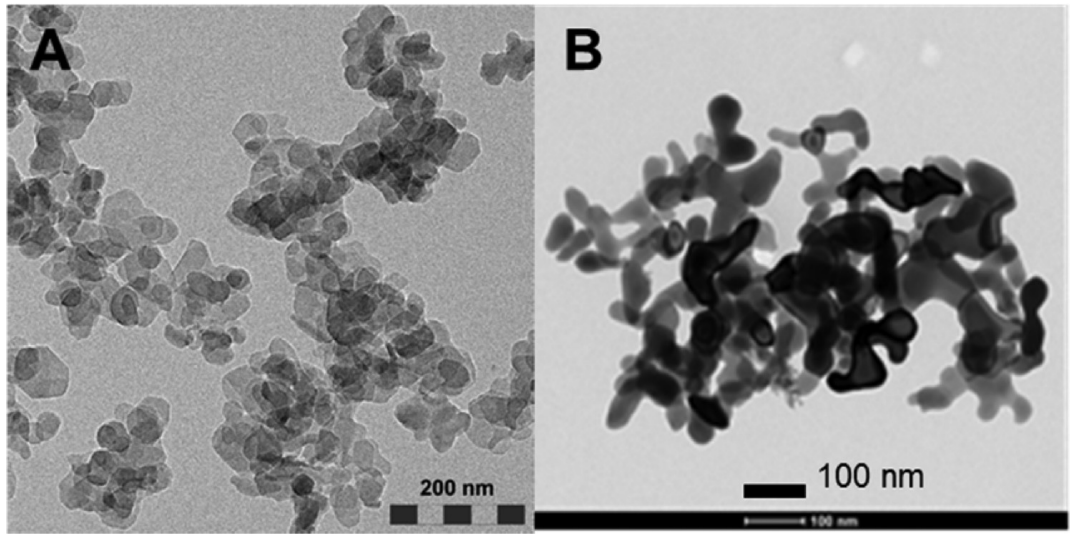

Figure 1. Representative electron microscopy images of the organic DPP (A) and the inorganic $\mathrm{Fe}_{2} \mathrm{O}_{3}$ pigment (B).

have superior thermal-, photo- and migration- stability. ${ }^{20}$ Nanoforms of pigments are favorable for certain applications for which they are marketed as "transparent" grades as they allow to achieve high transparency and brilliance with low light scattering. ${ }^{21}$ The public report of the French nanomaterials registry listed organic pigments, specifically diketopyrrolopyrroles (DPP), on 13th rank, and iron oxides on 15th rank with each 100-1000 t production volume. ${ }^{22}$ These substances are, however, not new: DPP was first patented in 1983 and was offered as transparent grade; DPP derivatives are known for their poor solubility in most organic matrices and solvents due to their tendency to form strong $\pi-\pi$ interactions and intermolecular hydrogen bonds. ${ }^{20}$ Iron oxide exists both by natural and manufactured nanoforms and non-nanoforms; both are red pigments used in various applications, some with outdoor uses, some in food contact materials (FCM). ${ }^{18}$ The substances are generally considered as safe, and earlier data on hazards actually was generated on their nanoform, but potentially not with targeted analytics for the nanoscale size range. Hence, it is worthwhile to reconsider the nanospecific safety of transparent pigment containing composites as the transformations of nanomaterials and nanoenabled products are known to require dedicated methods.

For the first time, we report here on release rates obtained on nanopigments, forms of the released fragments and an analysis of matrix degradations possibly facilitating their release. Our purpose with this extensive study was to provide an integrated vision of release during the use phase of these nanocomposites, and thus to enable modeling of environmental fate or consumer exposure.

\section{MATERIALS: FORMS OF NANOPIGMENTS MIMICKING DIFFERENT LIFE CYCLE STAGES}

To study the release behavior of nanopigments from a polymer matrix, two different nanoscale pigments were chosen: an organic diketopyrrolopyrrole (DPP, Red 254) and an inorganic, iron-based $\left(\mathrm{Fe}_{2} \mathrm{O}_{3}\right.$, Red 101) pigment. Both pigments are well suited for automotive effect finishes and are marketed as transparent grades. Representative electron microscopy images of both pigments are presented in Figure 1 showing agglomerates with primary particles in the $\mathrm{nm}$ range with a number-based median particle diameter of $43 \pm 14 \mathrm{~nm}$ for the organic and $35 \pm 20 \mathrm{~nm}$ for the inorganic pigment. Specific BET surface area was determined to $94 \mathrm{~m}^{2} / \mathrm{g}$ for the DPP and $30 \mathrm{~m}^{2} / \mathrm{g}$ for the iron-based pigment. Both pigment have no contaminations $>0.1 \%$, but DPP contains traces of $\mathrm{Si}$ and $\mathrm{Br}<$
$0.1 \%$, and $\mathrm{Fe}_{2} \mathrm{O}_{3}$ contains 32 ppm of $\mathrm{Cr}$ from the raw materials. More data on physicochemical properties of the two pigments are summarized in Table S1 in Supporting Information (SI).

Different life cycle stages of the nanopigments and the pure $\mathrm{PE}$ reference material were produced and investigated equally. First, the pigments were formulated into the polymer by mixing the powders with low-density polyethylene (LDPE) to achieve a good dispersion and facilitate further processing. These socalled masterbatches containing $10 \%$ of the organic pigment and $35 \%$ of the inorganic pigment, respectively, were diluted to concentrations of $0.2 \%$ for the DPP and $1 \%$ for the iron-based pigment into high-density polyethylene (HDPE, Sabic M80064-00900, see also SI Table S2) by hot melt extrusion resulting in granules with cylindrical sizes of approximately 4 $\mathrm{mm}$ length and $2 \mathrm{~mm}$ diameter.

To simulate the use phase of the materials, plates with dimensions of $5 \times 5 \times 0.1 \mathrm{~cm}^{3}$ for the organic pigment and 2.7 $\times 2.7 \times 0.3 \mathrm{~cm}^{3}$ for the inorganic pigment were produced from these granules by melt processing. These plates can be regarded as representative for final products such as car bumpers or consumer devices, including packaging with food contact. Consistently with this latter application, we ensured that the HDPE plastic and the pigments chosen for this study are in fact approved as food contact materials. In case of the organic pigment, both plates with and without $0.15 \%$ of an UV stabilizer (Hindered Amine Light Stabilizer, HALS) were produced to investigate the effect of an UV stabilizer on release behavior.

Additionally, granules were cryo-milled to produce fragments, mimicking debris that can be emitted from the materials, as a result of various treatments applied within the use phase or during disposal. ${ }^{23}$ granulegranule The milled fragments can be regarded as representative to what the environment or consumers are most likely exposed to and comprise the same material compared to granules and plates, but have a greatly increased surface $\left(0.05\right.$ and $0.06 \mathrm{~m}^{2} / \mathrm{g}$ for OrgPig_PE_FP and $\mathrm{Fe}_{2} \mathrm{O}_{3}$ PE_FP, respectively). A contamination of the polymer matrix by $\overline{\mathrm{Fe}}$ increases by each processing step (SI Table S2), but remains 3 orders of magnitude below the intentional $\mathrm{Fe}_{2} \mathrm{O}_{3}$ content. For the fragments of $\mathrm{Fe}_{2} \mathrm{O}_{3} \mathrm{PE}$ the total amount of surface-available iron, which might interact with surrounding media in the environment, was determined to $26 \pm 15 \mu \mathrm{g} / \mathrm{L}$ in the presence of a $1 \% \mathrm{HCl}$ solution $(24 \mathrm{~h}$, room temperature, 10 $\mathrm{g} / \mathrm{L})$ which is $0.04 \%$ of the initial amount of the inorganic pigment in PE. However, the iron concentration determined for the pure PE reference FP was clearly higher $(206 \pm 65 \mu \mathrm{g} / \mathrm{L}$, 
$0.32 \%$ ) which points to a Fe contamination stemming from the production process of the fragments by cryo-milling. Comparable findings were observed using citrate dithionite $(22 \mathrm{~g} / \mathrm{L})$ as an extractant $(20 \mathrm{~h}$, room temperature, $25 \mathrm{~g} / \mathrm{L}){ }^{24}$ Surface-accessible iron in $\mathrm{Fe}_{2} \mathrm{O}_{3} \mathrm{PE} F \mathrm{FP}$ was determined to $0.14 \%$ of the initial $\mathrm{Fe}$ amount present in the nanocomposite, whereas the Fe content in the pure reference PE_FP exceeded this value by far.

A summary of life cycle stages simulated in this study is given in Table 1 which additionally shows the composition of

Table 1. Summary of Simulated Life Cycle Stages and Compositions of Nanocomposites within the Organic and Inorganic Pigment Case Studies

\begin{tabular}{|c|c|c|c|}
\hline $\begin{array}{l}\text { life cycle } \\
\text { stage }\end{array}$ & form & composition & labeling \\
\hline formulated & granules & pure $\mathrm{PE}$ & PE_FOR \\
\hline use & plate & pure PE & PE_USE \\
\hline use/disposal & fragments & pure $\mathrm{PE}$ & PE_FP \\
\hline use & plate & $\begin{array}{l}\text { PE containing } \\
0.15 \% \text { UV } \\
\text { stabilizer }\end{array}$ & PE_UVstab_USE \\
\hline use & plate & $\begin{array}{c}0.2 \% \text { OrgPig in } \\
\text { PE }\end{array}$ & OrgPig_PE_USE \\
\hline use & plate & $\begin{array}{c}0.2 \% \text { OrgPig in } \\
\text { PE containing } \\
0.15 \% \text { UV } \\
\text { stabilizer }\end{array}$ & OrgPig_PE_UVstab_USE \\
\hline formulated & granules & $1 \% \mathrm{Fe}_{2} \mathrm{O}_{3}$ in $\mathrm{PE}$ & $\mathrm{Fe}_{2} \mathrm{O}_{3}$ PE_FOR \\
\hline use & plate & $1 \% \mathrm{Fe}_{2} \mathrm{O}_{3}$ in $\mathrm{PE}$ & $\mathrm{Fe}_{2} \mathrm{O}_{3} \mathrm{PE}_{-} \mathrm{USE}$ \\
\hline use/disposal & fragments & $1 \% \mathrm{Fe}_{2} \mathrm{O}_{3}$ in $\mathrm{PE}$ & $\mathrm{Fe}_{2} \mathrm{O}_{3}-\mathrm{PE} \_\mathrm{FP}$ \\
\hline
\end{tabular}

investigated materials. From the different forms of nanopigments (also shown for the whole inorganic pigment in PE case study in Figure 2A) mainly plates and fragmented products were used in this study. Release in food contact was performed using granules as they comprise a higher surface compared to the plates, but still have macroscopic dimensions. The pure PE polymer reference was investigated equally by using the same simulated life cycle stages. The assessment of production, handling and formulation of the pristine pigment is not part of the current study. For release assessment during the polymer melt production of macroscopic automotive parts from granules refer to Koivisto et al. ${ }^{25}$

\section{METHODS: RELEASE SCENARIOS}

In this study, we investigated the release behavior with nanospecific analysis methods and equally detailed tracking of polymer matrix transformations. Various release scenarios relevant for the application of the investigated nanopigments in car bumpers or food packaging, and for environmental and human exposure were examined, with a special focus on the use phase of the nanopigments' life cycle. Figure $2 \mathrm{~B}$ summarizes the four investigated release scenarios for the inorganic pigment case study, and also displays the life cycle stages of the nanopigments used for each scenario. Various scenarios were chosen according to the findings in literature describing chemical degradation and mechanical energy input as main pathways which influence release behavior of nanocomposites. ${ }^{4}$ Representative for the application of the nanopigments in car bumpers, release due to photochemical degradation of the polymer matrix by simulated sunlight was investigated. Here, two different release scenarios were considered: spontaneous release during weathering (scenario I) and release from aged nanocomposites induced by immersion and mechanical energy input (scenario II). ${ }^{26}$ Representative for the application in food contact materials, leaching of nanopigments in contact with food simulants was identified as a relevant release scenario (scenario III). During the use phase or disposal, fragments with embedded or protruding nanopigments can be emitted in both applications. To assess release from such fragments, cryo-
A)

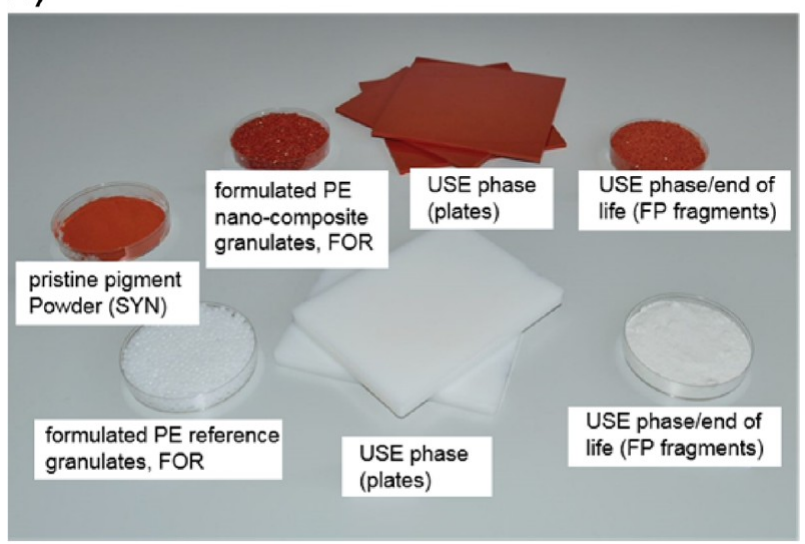

B)

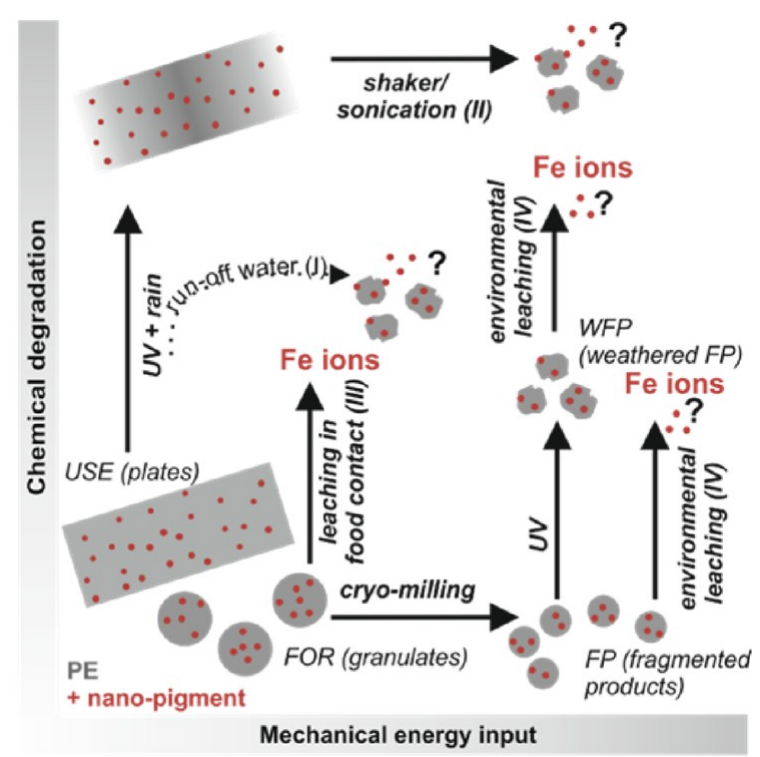

Figure 2. Experimental design of release scenarios studied in case of the inorganic $\mathrm{Fe}_{2} \mathrm{O}_{3}$ pigment case study. (A) Visualization of test materials to represent pristine pigment powder (SYN phase, not in focus here), nanoenabled product formulation (FOR phase) and use phase (USE phase and FP fragmented product). The user benefit of intense red color is clearly demonstrated by comparison to the plastic without pigments. (adapted with permission from ${ }^{23}$ ). (B) Multiple sequences of synergistic stresses map out the degradation scenarios during FOR and USE and phases. Secondary transformation of released $\mathrm{Fe}$ ions to $\mathrm{Fe}^{3+} \mathrm{OOH}$ or complexes with organic ligands is not depicted for simplicity, but the analysis differentiated ionic vs particulate species with quantitative, size-fractionating and imaging methods (see Table 2). 
Table 2. Overview of Methods for Release Sampling, Investigations on Matrix Degradation, And Detection/Characterization of Released Fragments for each Investigated Life Cycle Scenario (See Figure 2) for the Two Case Studies ${ }^{a}$

\begin{tabular}{|c|c|c|c|}
\hline material & release sampling & matrix degradation & detection/characterization of fragments \\
\hline OrgPig_PE_USE (plates) & immersion & $\begin{array}{c}\text { gloss retention, SEM, X-ray tomography, } \\
\text { FTIR }\end{array}$ & TEM, UV/vis \& AUC of immersion waters \\
\hline$\underset{\text { (plates) }}{\text { OrgPig_PE_UVstab_USE }}$ & immersion & $\begin{array}{c}\text { gloss retention, SEM, X-ray tomography, } \\
\text { FTIR }\end{array}$ & TEM, UV/vis \& AUC of immersion waters \\
\hline $\mathrm{Fe}_{2} \mathrm{O}_{3}{ }_{-} \mathrm{PE} \_\mathrm{FOR}$ (granules) & $\begin{array}{c}\text { leaching in food } \\
\text { stimulant }\end{array}$ & & ICP-MS of food contact simulant media \\
\hline $\mathrm{Fe}_{2} \mathrm{O}_{3} \_\mathrm{PE}$ _USE (plates) & $\begin{array}{l}\text { run-off water, } \\
\text { immersion }\end{array}$ & X-ray tomography, FTIR & $\begin{array}{c}\text { ICP-MS of runoff waters, TEM, UV/vis \& AUC of } \\
\text { immersion waters }\end{array}$ \\
\hline $\mathrm{Fe}_{2} \mathrm{O}_{3} \_\mathrm{PE} \_\mathrm{FP}$ (fragments) & environmental leaching & FTIR & (sp)ICP-MS of leaching waters \\
\hline
\end{tabular}

milling was applied as a representative mechanical process to produce debris which can be regarded as representative of what the environment or consumers are most likely exposed to. Release from these fragments was investigated by leaching in environmentally relevant media from as-produced and aged materials (scenario IV). For all scenarios standardized or wellestablished protocols and methods for release sampling, detection, and characterization of released fragments were applied, and are described in detail in the SI. Table 2 summarizes methods for release sampling, investigations on matrix degradation, and detection/characterization of released fragments.

\section{RESULTS}

Matrix Degradation by Simulated Sunlight. Morphological Degradation of Plates. As an indication of the condition of the plates' surface, gloss retention was studied at several weathering times for the organic pigment case study (Figure 3). No change in gloss could be observed for the pure

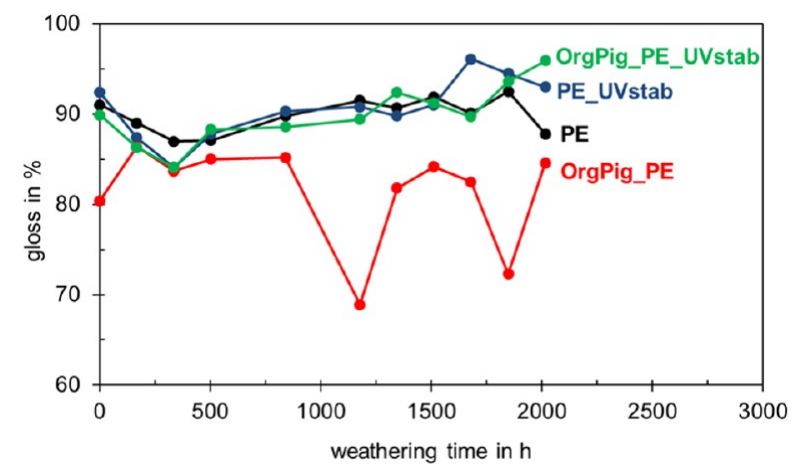

Figure 3. Gloss retention vs weathering time for the organic pigment nanocomposite and pure PE, both with and without UV stabilizer. No difference in gloss between the nanocomposite and the pure $\mathrm{PE}$ reference in the presence of the UV stabilizer.

PE reference as well as for the PE reference containing the UV stabilizer. The nanocomposite without the UV stabilizer showed a slight decrease in gloss, but no change in gloss was obtained in the presence of the UV stabilizer which prevented the surface from aging. This effect could be confirmed by scanning electron microscopy images of plates after weathering over 12 weeks (see SI Figure S2). Especially when using a UV stabilizer, there is no difference between the pure PE plate and the PE plate containing the organic pigment. All plates showed machining stripes on the surface, but there was no evidence of cracks or free, nanoscale pigment particles on the surfaces of aged plates.

In addition, plates of the nanocomposites and the pure PE reference were investigated by X-ray computed microtomography. Figure 4 shows $3 \mathrm{D}$ representations of as-produced plates and plates weathered for 12 weeks $(2016 \mathrm{~h}$ or $1944 \mathrm{~h}$ depending on the applied protocol). The PE matrix appears in blue, denser material in green or red. The as-produced plates (Figure 4A, C, and E) display a rather smooth surface with a few machining stripes. Dense particles can be observed for all plates as red spots, but their distribution is different for each investigated type of plate. In case of pure PE, particles with an irregular shape are present on the plate surface. Both the particle shape and the absence of these particles inside the plates point to a surface contamination, probably resulting from material handling or machining. In case of OrgPig_PE spherical particles are only observed inside the nanocomposite and probably consist of DPP agglomerates $>1 \mu \mathrm{m}$, whereas the vast majority of DPP remains undetected (resolution of $0.51 \mu \mathrm{m}$ ) as it is well dispersed within the PE matrix. In case of $\mathrm{Fe}_{2} \mathrm{O}_{3} \mathrm{PE}$, particles are present both at the surface and inside the plate. As these particles comprise similar shapes and X-ray absorptions independently from their location, they presumably consist of the inorganic $\mathrm{Fe}_{2} \mathrm{O}_{3}$ pigment. Again, only the pigment agglomerates $>1 \mu \mathrm{m}$ are visualized by X-ray tomography due to the limited resolution. However, it can be noticed that more agglomerates are present in case of $\mathrm{Fe}_{2} \mathrm{O}_{3}$ compared to DPP.

Aged OrgPig_PE plates seems rather unchanged compared to as-produced samples (Figure 4B), also when using a UV stabilizer (not shown). The surface density, which is high compared to the bulk for as-produced plates, seems to decrease during aging, maybe due to the volatilization of material. On the contrary, both $\mathrm{PE}$ and $\mathrm{Fe}_{2} \mathrm{O}_{3} \mathrm{PE}$ plates weathered according to the modified ISO $4892-2 \mathrm{~A}$ protocol (see SI) show a densification of the exposed surface (Figure 4D and F). In addition, an increased number of dense particles can be observed on the surface of the PE reference which most probably results from a deposition of material during weathering. However, there is no evidence for an accumulation of nanofillers on the nanocomposites surfaces as was reported for polyamide composites. ${ }^{27,28}$

No significant matrix degradation can be observed for PE and OrgPig_PE, but in case of $\mathrm{Fe}_{2} \mathrm{O}_{3}$ PE cracks are present (Figure $4 \mathrm{~F}$ ) which were not visible by naked eye nor by SEM. They can be observed after 8 weeks of weathering (1288 h) with a maximum depth of $15 \pm 2 \mu \mathrm{m}$. They are predominantely present close to $\mathrm{Fe}_{2} \mathrm{O}_{3}$ agglomerates, but do not show any preferential direction (not shown). With increasing weathering time, density, length and depth of the cracks are growing which 


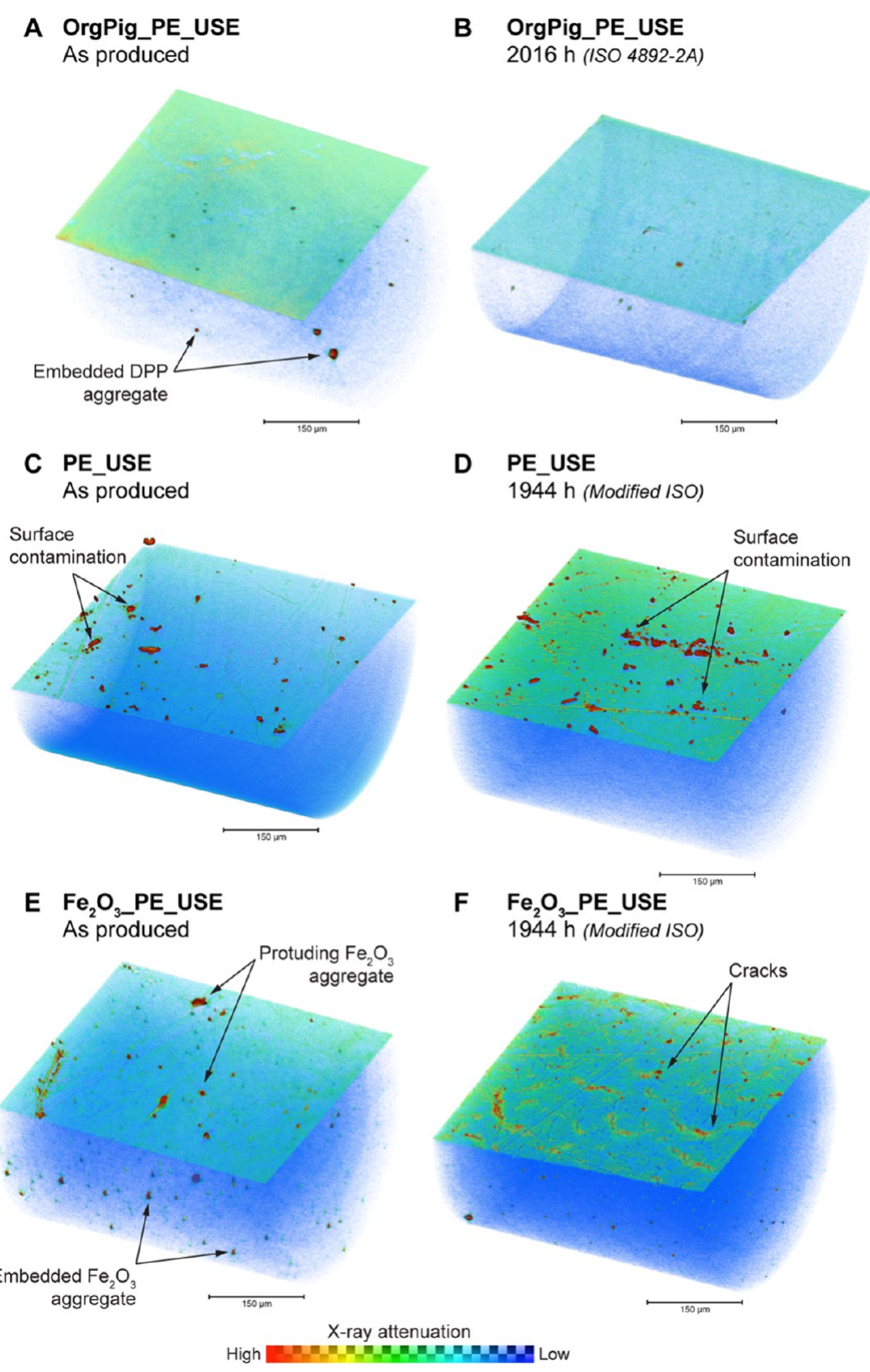

Figure 4. Volume rendering of X-ray computed tomography analysis. OrgPig PE USE (A), PE USE (C), and $\mathrm{Fe}_{2} \mathrm{O}_{3}$ PE USE (E) plates before weathering. OrgPig_PE_USE weathered for $2016 \mathrm{~h}$ (12 weeks) according to ISO $4892-2 \mathrm{~A}$ protocol (B), PE_USE (D) and $\mathrm{Fe}_{2} \mathrm{O}_{3}{ }_{-} \mathrm{PE} \_\mathrm{USE}$ (F) weathered according to the modified ISO $4892-2 \mathrm{~A}$ protocol for $1944 \mathrm{~h}$ (12 weeks). Absorption intensities were normalized to provide a comparable color map. Low X-ray attenuation, corresponding to light material, appears in blue, high attenuation, indicating dense material, in red.

is illustrated in the tomography movie provided in the SI. After 12 weeks $(1944 \mathrm{~h})$ cracks are $23 \pm 2 \mu \mathrm{m}$ deep, and after prolonged irradiation until 18 weeks $(2928 \mathrm{~h})$ they reach $31 \pm$ $2 \mu \mathrm{m}$. A densification of HDPE surfaces during weathering was already reported, ${ }^{29}$ and can arise from a cross-linking phenomenon and/or chemi-crystallization of the small and highly mobile molecules generated by chain scission. ${ }^{30}$ This results in a denser packing of the material and a volume contraction with respect to the unoxidized polymer, which can eventually lead to the formation of cracks. In addition, the presence of a filler inside a polymer matrix can create a discontinuity in the physicial properties of the material. ${ }^{31,32}$ The resulting uneven stress during thermal dilatation can lead to crack formation as well. The influence of different mineral fillers on crack formation was investigated by Yang et al. ${ }^{33}$
Among six fillers studied four (sericite, mica, kaolin and diatomite) induced cracking to a lower or larger extent, while talc or wollastonite did not modify the behavior of HDPE under natural weathering. Based on FTIR data, Yang et al. conclude that crack formation is related to a photo-oxidation of PE enhanced in the presence of some filling agent. This hypothesis will be tested for PE, OrgPig_PE and $\mathrm{Fe}_{2} \mathrm{O}_{3} \mathrm{PE}$ in the next section.

Chemical Degradation of Materials. FTIR is highly established to track polymer matrix degradation in general ${ }^{34,35}$ and of polyolefins specifically..$^{29,32,33,36,37}$ FTIR spectra were obtained for as-produced materials (plates and fragmented product) of both case studies as a reference for the evaluation of aged materials ( SI Figure S3). The samples mainly display absorption bands corresponding to $\mathrm{C}-\mathrm{H}$ stretching (2914 and 

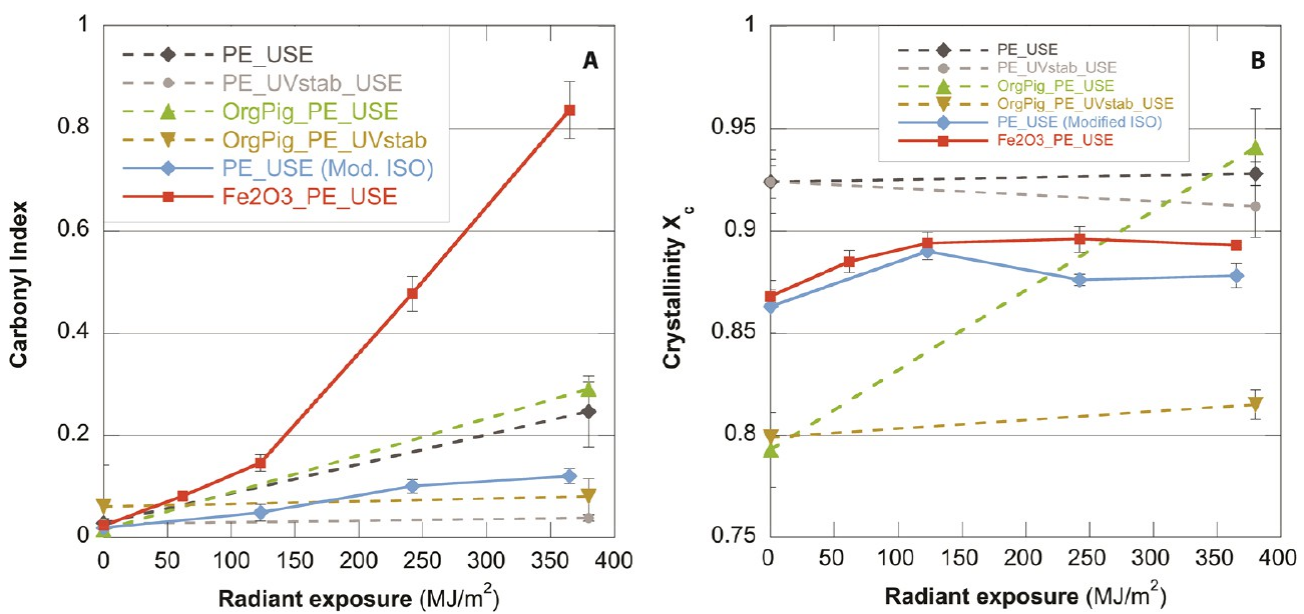

Figure 5. Evolution of carbonyl index (A) and crystallinity (B) of PE and nanocomposite plates as a function of radiant exposure during weathering. The error bars represent the standard deviation calculated for the three investigated replicates.

$\left.2846 \mathrm{~cm}^{-1}\right)$, bending $\left(1471\right.$ and $\left.1462 \mathrm{~cm}^{-1}\right)$ and rocking $(731$ and $\left.719 \mathrm{~cm}^{-1}\right)$. No major difference can be observed between the different nanocomposites, nor between the investigated life cycle stages.

During aging the growth of an absorption band around 1720 $\mathrm{cm}^{-1}$ is evidenced for plate samples (SI Figure S4 A-D). This can be attributed to the formation of $\mathrm{C}=\mathrm{O}$ bonds indicating an oxidation of the PE matrix under UV irradiation. In contrast, no $\mathrm{C}=\mathrm{O}$ band was detected in case of fragmented products even after a weathering time of 12 weeks (Figure S4E-F). In case of $\mathrm{Fe}_{2} \mathrm{O}_{3}$ PE FP a slight bump emerges after 8 weeks (1312h), while for $\overline{\mathrm{Fe}}_{2} \mathrm{O}_{3}$ PE plates oxidation was obvious since the third week of aging. However, an artifact of measurement cannot be totally excluded, as the irregular shape of fragmented products makes FTIR analysis less reliable.

In order to compare the progress of oxidation between the different samples, a carbonyl index was calculated using eq 1

$$
\text { carbonyl index }=\frac{A_{1800-1680}}{A_{1490-1425}}
$$

where $A_{1800-1600}$ and $A_{1490-1425}$ represent the integrated absorbance of the carbonyl and $\mathrm{C}-\mathrm{H}$ bending bands, respectively. The evolution of the carbonyl index as a function of radiant exposure is shown in Figure 5A for PE, OrgPig_PE and $\mathrm{Fe}_{2} \mathrm{O}_{3}$ PE plates. PE and OrgPig_PE weathered according to ISO $4892-2 \mathrm{~A}$ display a very similar increase in carbonyl index. In presence of the UV stabilizer no increase can be observed, proving the effectiveness of the UV stabilizer to prevent photo-oxidation. Aging with the modified protocol leads to a stronger oxidation in case of $\mathrm{Fe}_{2} \mathrm{O}_{3} \mathrm{PE}$ compared to pure PE. This effect is not necessarily related to the stronger light absorption of the red nanocomposite. A similar light absorption is expected for $\mathrm{Fe}_{2} \mathrm{O}_{3}$ PE and OrgPig_PE, but the latter one does not show an enhanced oxidation compared to pure PE (both weathered according ISO 4892-2A). Therefore, we assume that iron accelerates the photo-oxidation and chain scission of the PE matrix by acting as an electron acceptor or by mediating reactive oxygen species (ROS) production and hydroperoxide formation. See the SI for a more detailed analysis of the carbonyl index.

As the crystallinity of PE samples is assumed to influence cracking, the following empirical relationship proposed by Zerbi et al. was applied: ${ }^{38}$

$$
X_{\mathrm{c}}=1-\frac{\left(1-I_{\mathrm{a}} / I_{\mathrm{b}}\right) / 1.233}{1+I_{\mathrm{a}} / I_{\mathrm{b}}}
$$

where $X_{c}$ is the crystalline content, and $I_{\mathrm{a}}$ and $I_{\mathrm{b}}$ are the absorbance of the peaks at 731 and $719 \mathrm{~cm}^{-1}$. The constant 1.233 corresponds to the relations of the intensity bands of fully crystalline HDPE. ${ }^{38}$ The crystallinity of the different PE plates investigated is shown as a function of radiant exposure in Figure 5B. For as-produced plates, materials can be categorized in three groups based on their initial crystalline content: $\mathrm{PE}$ and PE_UVstab $>$ PE (mod. ISO) \& $\mathrm{Fe}_{2} \mathrm{O}_{3} \_\mathrm{PE}>$ OrgPig_PE and OrgPig_PE_UVstab. This indicates that incorporation of the inorganic $\mathrm{Fe}_{2} \mathrm{O}_{3}$ pigment into the PE matrix had no impact on the polymer crystallinity, whereas the addition of the organic pigment reduced the crystalline fraction in the nanocomposite.

In case of the original ISO protocol 4892-2A, no significant changes can be observed for PE (with or without UV stabilizer) compared to as-produced plates. In contrast, the crystallinity of OrgPig_PE obviously increases during weathering, finally reaching the crystallinity of pure PE. However, using an UV stabilizer, the crystallinity of OrgPig_PE remains nearly unchanged during weathering, suggesting that recrystallization of OrgPig_PE is a consequence of its photo-oxidation. $\mathrm{Fe}_{2} \mathrm{O}_{3} \mathrm{PE}$ and $\mathrm{PE}$ weathered according to the modified protocol show an increasing crystallinity up to 4 weeks weathering $\left(123 \mathrm{MJ} / \mathrm{m}^{2}\right)$. Afterward, the crystalline content remains constant or slightly decreases for pure PE. At the end of weathering $\left(363 \mathrm{MJ} / \mathrm{m}^{2}\right)$ OrgPig_PE, $\mathrm{Fe}_{2} \mathrm{O}_{3} \mathrm{PE}$, and PE aged by the modified protocol show an increase on crystallinity of $18.7 \% \pm 4.8 \%, 3.0 \% \pm 0.3 \%$, and $1.8 \% \pm 1.6 \%$, respectively.

Material Loss. During weathering a continuous decrease in plate mass was observed for both PE reference and inorganic pigment nanocomposite. Material loss was, however, higher for the nanocomposite. After 12 weeks of weathering by simulated sunlight and rain, the weight of nanocomposite plates was reduced by $4.4 \mathrm{mg} \pm 0.1 \mathrm{mg}$ compared to their initial mass, while reference plates had only lost $1.9 \mathrm{mg} \pm 0.2 \mathrm{mg}$. These amounts account for 0.16 and $0.07 \%$ of initial plate mass, respectively. It was shown before that the release of particulate fragments is a minor component of the total mass loss, which is instead dominated by volatile organics. ${ }^{28,34}$ Such volatile compounds are formed during the oxidation of the PE matrix. The stronger oxidation measured for $\mathrm{Fe}_{2} \mathrm{O}_{3} \mathrm{PE}$ compared to 
pure PE presumably explains the higher mass loss of nanocomposite plates. Moreover, the presence of $1.9 \%$ low density, low molar mass PE (LDPE wax) within the $\mathrm{Fe}_{2} \mathrm{O}_{3}$ nanocomposite sample, stemming from the nanopigment masterbatch and therefore only present in the nanocomposite, might facilitate evaporation from the matrix in case of the nanocomposite. If that evaporation and mass loss was a localized event at a well-defined surface layer -similar to a sputtering treatment- the volatilization of PE would leave 60.4 $\pm 1.5 \mathrm{mg} / \mathrm{m}^{2}$ of $\mathrm{Fe}_{2} \mathrm{O}_{3}$ not embedded anymore in the matrix. A fraction thereof could be released more easily, depending on shear forces in the specific scenario. However, the tomography shows that the cracks (relating to mass loss) propagate into the polymer. This indicates that weathering-induced mass loss is not a sputtering-like event, so that the actual mass of released fragments needs to be measured and cannot be extrapolated from mass loss.

Released Fragments during and after Matrix Degradation by Simulated Sunlight. Quantification of Free (Dissolved and Particulate) Fe in Runoff Waters (Scenario I).

Release rates determined by ICP-MS for free Fe (dissolved and particulate) in weathering periods of 46 or $72 \mathrm{~h}$ in runoff waters collected during aging of plates of the inorganic pigment case study are summarized in Table 3. Iron was detected in all runoff

Table 3. Release Rates Calculated for Run-off Waters Collected during Aging of Inorganic Pigment-Containing and PE Reference Plates $\left(\mathrm{Fe}_{2} \mathrm{O}_{3} \mathrm{PE}\right.$ USE and PE USE)

\begin{tabular}{ccrc} 
& & \multicolumn{2}{c}{ release rate $\left(\mathrm{mg} / \mathrm{m}^{2}\right)$} \\
\cline { 3 - 4 } sampling time $(\mathrm{h})$ & $\mathrm{UV}$ dose $\left(\mathrm{MJ} / \mathrm{m}^{2}\right)$ & \multicolumn{1}{c}{$\mathrm{PE}$ USE } & $\mathrm{Fe}_{2} \mathrm{O}_{3} \mathrm{PE} \_\mathrm{USE}$ \\
46 & 7 & $5.99 \pm 0.14$ & $5.45 \pm 0.23$ \\
256 & 47 & $9.97 \pm 0.17$ & $8.94 \pm 0.27$ \\
492 & 94 & $12.62 \pm 0.54$ & $11.07 \pm 0.39$ \\
538 & 101 & $11.35 \pm 0.35$ & $15.07 \pm 1.52$ \\
748 & 137 & $11.31 \pm 0.33$ & $8.93 \pm 0.14$ \\
984 & 184 & $18.47 \pm 0.55$ & $78.02 \pm 1.57$ \\
1030 & 194 & $5.14 \pm 0.12$ & $44.96 \pm 0.84$ \\
1240 & 234 & $42.48 \pm 1.02$ & $61.65 \pm 0.74$ \\
1334 & 252 & $0.15 \pm 0.01$ & $0.36 \pm 0.01$ \\
1452 & 274 & $26.12 \pm 0.67$ & $0.54 \pm 0.02$ \\
1498 & 281 & $0.88 \pm 0.04$ & $1.08 \pm 0.03$ \\
1708 & 320 & $1.33 \pm 0.04$ & $2.04 \pm 0.08$ \\
1826 & 342 & $0.86 \pm 0.03$ & $0.37 \pm 0.01$ \\
1944 & 364 & $30.59 \pm 0.56$ & $1.64 \pm 0.06$ \\
& & &
\end{tabular}

waters, including those obtained on neat PE_USE plates, which did not originally contain $\mathrm{Fe}_{2} \mathrm{O}_{3}$ nanoparticles. Therefore, these detected concentrations cannot be assigned to pigment release and most probably come from an inherent or environmental contamination (production process, climatic chamber, glass, water tank, etc.). The levels determined for both sample types are very similar (except on specific sampling times with singularities of far higher concentrations than before and after). If $\mathrm{Fe}_{2} \mathrm{O}_{3}$ is released at all, the corresponding iron amount is negligible with respect to contamination background. We assume that a contribution of $10 \%$ from $\mathrm{Fe}_{2} \mathrm{O}_{3}$ nanoparticulate pigment to the total release would have been observed by its dependency on UV dose (comparing sampling times) and pigment content (comparing PE_USE vs $\mathrm{Fe}_{2} \mathrm{O}_{3}$ PE_USE). Based on this assumption, and using mean $\overline{F e}$ releases measured after $1334 \mathrm{~h}$, which displayed a lower environmental contamination level, we deduce a limit of detection (LoD) for the Fe release rate of $0.1 \mathrm{mg} / \mathrm{m}^{2}$ for periods of 46 or $72 \mathrm{~h}$ weathering ( 0.007 or $0.012 \mathrm{mg} / \mathrm{MJ})$. Integrated over the whole weathering duration and assuming constant release over the whole time, this would result in $3.6 \mathrm{mg} / \mathrm{m}^{2}$ Fe released over 12 weeks. This value is an estimation for a worst-case scenario and can be regarded as a maximum release rate for this study.

Quantification and Characterization of Released Fragments in Immersion Waters (Scenario II). The release of fragments from as-produced and weathered plates, induced by immersion and immersion followed by sonication was measured by UV/Vis spectroscopy (Figure 6). In the NanoRelease interlaboratory comparison, UV/Vis turned out to be the most sensitive technique to detect any increase of molecularly dissolved or particle release, mostly by turbidity (particle light scattering) effects. ${ }^{26}$ For both case studies release induced by the sonication protocol resulted in higher optical densities than immersion alone which is in good agreement with the literature. ${ }^{26}$ However, optical densities measured for the nanocomposite plates were similar or even lower compared to signals obtained for pure PE reference plates. Under simple immersion no increase in signals was observed for aged materials compared to the as-produced samples. However, when sonication was applied a higher optical density was measured after aging, although there was no consistent trend with increasing weathering time. The presence of an UV stabilizer also did not significantly influence signals. Within the experimental error, we did not observe a significant increase in this study by either the nanoscale additives, nor by UV dose, pointing to a matrix-dominated release behavior.

Quantification of released amounts of fragments in immersion waters was investigated by analytical ultracentrifugation. The measured release rates in $\mathrm{mg} / \mathrm{m}^{2}$ are presented in Figure S5 in SI. Both sedimentation and flotation were investigated in case of OrgPig_PE as the density of the matrix which is lower than the density of water might have led to a flotation of pure PE fragments and PE fragments which contain the organic pigment. Fragments of pure pigment settled down due to their density which is higher than the density of water. Release in both case studies was in the range of the AUC quantification limit of $10 \mathrm{ppm}\left(\sim 10 \mathrm{mg} / \mathrm{m}^{2}=0.03 \mathrm{mg} / \mathrm{MJ}\right)$ or even below. Also considering the uncertainty of measurement of $10 \mathrm{mg} / \mathrm{m}^{2}$, displayed in the diagrams as error bars, one can consider the amount of released fragments below the limit of AUC quantification. This result is in good agreement with the literature which also shows low release rates from PE matrices as well as a matrix-dominated release behavior., ${ }^{6,39}$

Figure 7 shows representative electron microscopy images of immersion waters achieved with nanocomposite plates weathered over 4 or 12 weeks followed by stepwise immersion and sonication. There was no evidence of fragments in immersion waters of the organic pigment case study and of pure PE plates. In contrast, fragments were visible in immersion waters of the inorganic pigment case study. These fragments contained $\mathrm{Fe}$ among others such as $\mathrm{Cr}$ which was verified by EDX (energy dispersive X-ray spectroscopy). The elemental ratio $\mathrm{Cr} / \mathrm{Fe}$ of the fragments does not match the composition of the pristine $\mathrm{Fe}_{2} \mathrm{O}_{3}$ pigments. Some fragments showed ironcontaining agglomerate structures (Figure $7 \mathrm{~B}$ ), however the size of the constituent particles is smaller (median diameter of $12,18,13 \mathrm{~nm}$ for 4,8 , and 12 weeks of aging) compared to the size range of the pristine pigment powder $(35 \mathrm{~nm})$ during TEM analysis (size distributions are shown in SI Figure S6). In addition, the near-spherical shape is not identical to the as- 


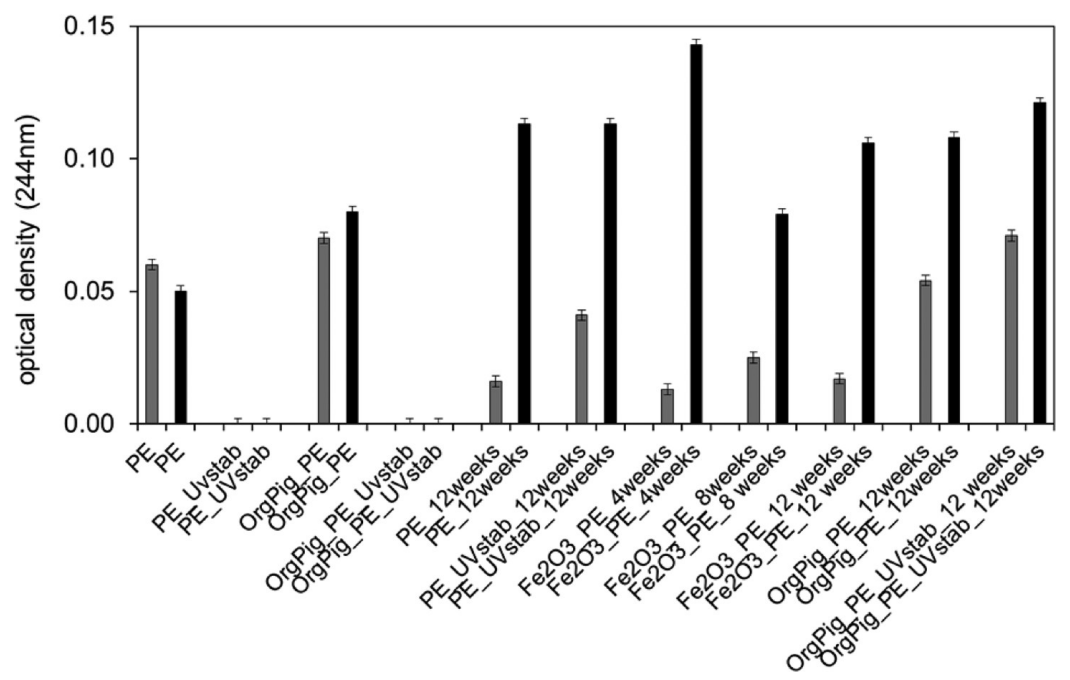

Figure 6. Result of UV/vis spectroscopy given as optical density at a wavelength of $244 \mathrm{~nm}$ for as-produced plates and plates that were weathered for $4,8,12$ weeks as indicated. Release sampling in both cases was performed by $24 \mathrm{~h}$ immersion (gray) and $24 \mathrm{~h}$ immersion followed by $1 \mathrm{~h}$ sonication (black). Error bars indicate the systematic error of UV/Vis spectrocsopy.
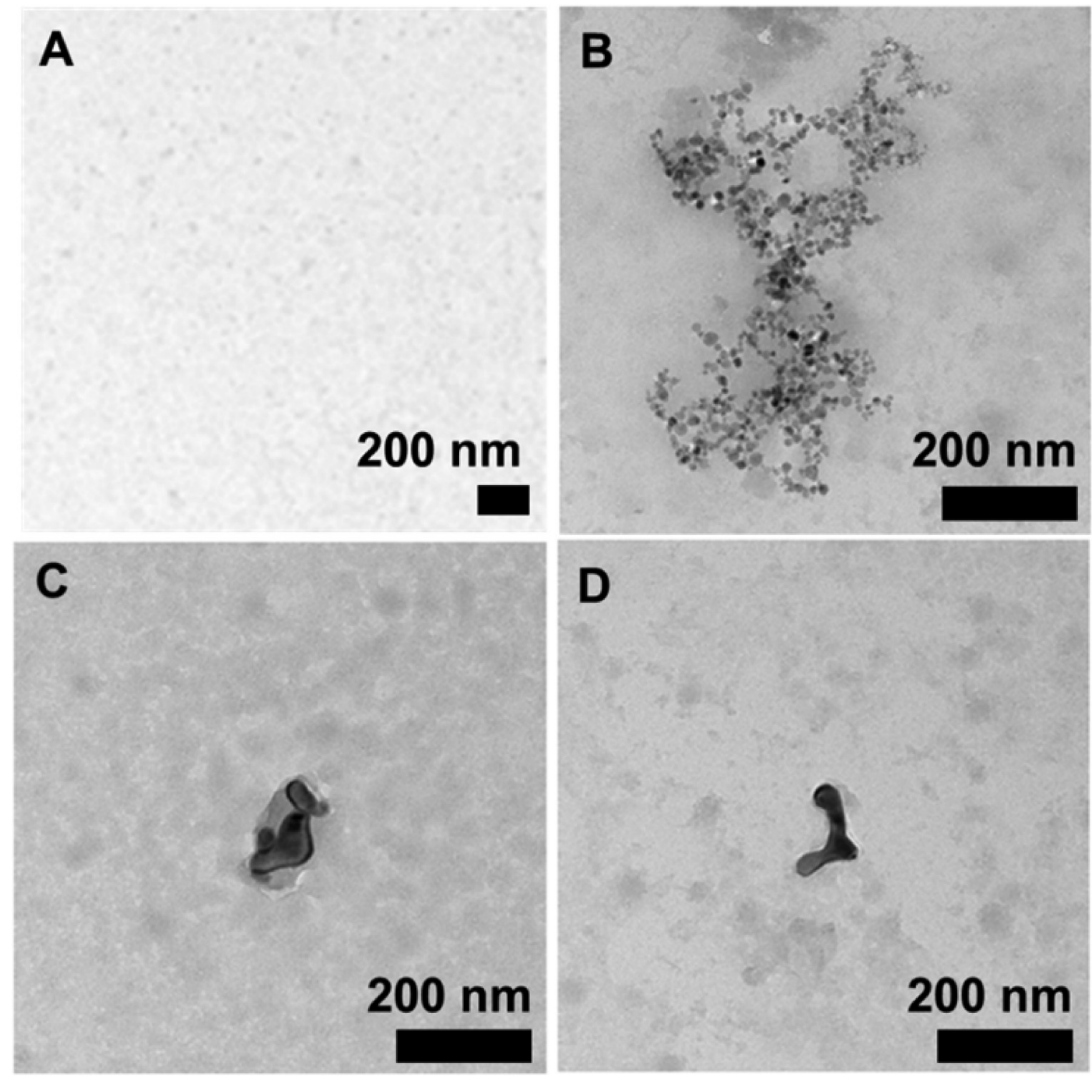

Figure 7. Representative TEM images of immersion waters of OrgPig_PE after wet weathering over 12 weeks (A) and immersion followed by sonication of $\mathrm{Fe}_{2} \mathrm{O}_{3} \_\mathrm{PE}$ after weathering over 4 weeks $(\mathrm{B}, \mathrm{C})$ and 12 weeks (D). See SI Figure S6 for size distribution analysis of TEM images.

produced iron oxide. We speculate that the fragments in immersion waters are transformed pigment particles resulting from a photo-oxidation of $\mathrm{PE}$ associated with a reduction of $\mathrm{Fe}^{3+}$ to $\mathrm{Fe}^{2+}$. As $\mathrm{Fe}^{2+}$ is unstable under our $E_{\mathrm{h}}$ and $\mathrm{pH}$ conditions, it is immediately reoxidized and polymerizes into $\mathrm{Fe}^{3+} \mathrm{OOH}$ particles. This is supported by the known redox cycles of Fe colloids. ${ }^{40,41}$ However, as determined by AUC, the absolute content in the immersion water was below $10 \mathrm{ppm}$.
Quantification of Fe (Dissolved, Particulate, And Embedded) Released in Food Contact (Scenario III). The iron concentrations determined for leaching over 10 days in contact with all three investigated food simulants (pure Milli-Q water, Milli-Q water with $10 \%$ ethanol, or Milli-Q water with $3 \%$ acetic acid) were below or in the range of the ICP-MS detection limit of $1.5 \mu \mathrm{g} / \mathrm{L}$ and below the limit of quantification of $3.4 \mu \mathrm{g} / \mathrm{L}$ for both inorganic pigment in $\mathrm{PE}$ and pure $\mathrm{PE}$ granules. Related to the initial amount of $\mathrm{Fe}_{2} \mathrm{O}_{3}$ present in the 
nanocomposite, less than $0.0002 \%$ of $\mathrm{Fe}$ leached into the different food contact media.

Quantification of Free Fe (Dissolved and Particulate) Released by Leaching (Scenario IV). The leaching of iron (dissolved and particulate) from $\mathrm{Fe}_{2} \mathrm{O}_{3} \mathrm{PE}$ fragments was assessed in three environmentally relevant media, namely MilliQwater (DIW, $\mathrm{pH}$ 6.5), moderately hard water (EPA, $\mathrm{pH} 7.6$ ), and water containing Suwannee River Humic Acid (SRNOM, 1 $\mathrm{mg} / \mathrm{L}$ dissolved organic carbon (DOC), $\mathrm{pH}$ 8.0) and monitored by single-particle-ICP-MS (sp-ICP-MS). Sp-ICP$\mathrm{MS}$ is very powerful for release measurements as it meets the requirements of very high sensitivity $(\mathrm{ng} / \mathrm{L})$, high throughput, and detects particle number concentration and particle mass. ${ }^{42,43}$ The iron concentrations released over 3 months (see methods in SI) were measured by ICP-MS and are summarized in Table 4. Measured concentrations for the pure

Table 4. Iron Concentrations in Leaching Media after 3 Months for As-Produced FP of the $\mathrm{Fe}_{2} \mathrm{O}_{3}$ Containing PE Nanocomposite ${ }^{a}$

\begin{tabular}{clc} 
material & \multicolumn{1}{c}{ medium } & $\begin{array}{c}\text { Fe leached after control sample } \\
\text { subtraction }(\%)\end{array}$ \\
$\mathrm{Fe}_{2} \mathrm{O}_{3} \_\mathrm{PE}$ & DIW, 3 months & 0.00239 \\
$\mathrm{Fe}_{2} \mathrm{O}_{3} \mathrm{PE}$ & EPA, 3 months & 0.00155 \\
$\mathrm{Fe}_{2} \mathrm{O}_{3} \mathrm{PE}$ & $\begin{array}{c}\text { SRNOM, 3 } \\
\text { months }\end{array}$ & 0.00163 \\
& mons
\end{tabular}

${ }^{a}$ Due to an iron contamination during weathering of the materials, a calculation of leached $\mathrm{Fe}$ is not possible for the aged materials.

PE reference were already subtracted. In all investigated media, iron release was very low. When compared to the initial amount present in the nanocomposite only about $0.002 \%$ of $\mathrm{Fe}$ leached into the media which is equal to $0.3 \mathrm{mg} / \mathrm{m}^{2}$. Slightly higher leaching was observed when using DIW as leaching media. In case of the weathered samples, iron contents in all leaching media were higher for pure $\mathrm{PE}$ reference compared to the $\mathrm{Fe}_{2} \mathrm{O}_{3}$ containing nanocomposite material. This indicates an iron contamination most likely coming from the production process $(4 \mathrm{mg} / \mathrm{kg}$ Fe in pure PE reference, see SI Table S2) or from the climate chamber which was used for aging of the materials. As this sample background dominates the signals, a calculation of $\mathrm{Fe}$ leached from the pigment content of weathered nanocomposite FP cannot be calculated. The fact that the content of $5800 \mathrm{mg} / \mathrm{kg}$ iron in nanopigments does not add significant release over the background release from $4 \mathrm{mg} /$ $\mathrm{kg}$ iron contamination (SI Table S2) indicates strong containment of the nanopigments with no significant release pathway.

The presence of Fe particles in leaching media was proven by sp-ICP-MS (SI Figure S7). Both ionic offset and particulate events were observed. Fe-containing particle number concentrations were calculated using 5sigma iterative algorithm ${ }^{43}$ and are reported in Table 5. Even in pure leaching media, some particles were detected, especially for EPA and SRNOM media. In comparison to pure PE reference only in DIW a slight increase of $\mathrm{Fe}$ particle number was detected for the nanocomposite, in EPA and SRNOM the Fe particle number even decreased. In case of the aged materials, no significant change was observed in DIW between pure PE and the nanocomposite. For EPA and SRNOM Fe particle number in case of the weathered nanocomposite was significantly lower than for the reference. Consistently with the results of the total
Table 5. Fe Particle Number Concentration in Leachates from As-Produced and Weathered Fragmented Products of $\mathrm{PE} \mathrm{Fe}_{2} \mathrm{O}_{3}$ and Pure PE Reference in Environmentally Relevant Media Determined by sp-ICP-MS (Time-Resolved Scans Documented in SI Figure S7)

\begin{tabular}{|c|c|c|c|c|}
\hline $\begin{array}{l}\text { investigated } \\
\text { material }\end{array}$ & $\begin{array}{l}\text { leachate } \\
\text { medium }\end{array}$ & $\begin{array}{c}\text { average } \\
\text { particle } \\
\text { number per } \\
\text { run }(n=2)\end{array}$ & $\begin{array}{l}\text { particles per } \mathrm{mL} \\
\quad(n=2)\end{array}$ & $\begin{array}{l}\text { significance } \\
\text { vs control }\end{array}$ \\
\hline & DIW & $8 \pm 2$ & $429 \pm 121$ & \\
\hline & EPA & $147 \pm 5$ & $8371 \pm 283$ & \\
\hline & SRNOM & $147 \pm 17$ & $8400 \pm 970$ & \\
\hline PE & DIW & $5 \pm 1$ & $286 \pm 81$ & \\
\hline $\mathrm{Fe}_{2} \mathrm{O}_{3}{ }_{-} \mathrm{PE}$ & DIW & $33 \pm 8$ & $1886 \pm 485$ & increase \\
\hline $\begin{array}{c}\text { weathered } \\
\text { PE }\end{array}$ & DIW & $310 \pm 18$ & $17686 \pm 1010$ & \\
\hline $\begin{array}{l}\text { weathered } \\
\mathrm{Fe}_{2} \mathrm{O}_{3} \mathrm{PE}\end{array}$ & DIW & $234 \pm 23$ & $13371 \pm 1293$ & $\begin{array}{c}\text { no } \\
\text { significant } \\
\text { change }\end{array}$ \\
\hline $\mathrm{PE}$ & EPA & $275 \pm 1$ & $15714 \pm 81$ & \\
\hline $\mathrm{Fe}_{2} \mathrm{O}_{3} \mathrm{PE}$ & EPA & $81 \pm 8$ & $4629 \pm 485$ & reduction \\
\hline $\begin{array}{c}\text { weathered } \\
\text { PE }\end{array}$ & EPA & $611 \pm 6$ & $34886 \pm 364$ & \\
\hline $\begin{array}{l}\text { weathered } \\
\mathrm{Fe}_{2} \mathrm{O}_{3} \mathrm{PE}\end{array}$ & EPA & $33 \pm 16$ & $1886 \pm 889$ & reduction \\
\hline $\mathrm{PE}$ & SRNOM & $118 \pm 29$ & $69257 \pm 1657$ & \\
\hline $\mathrm{Fe}_{2} \mathrm{O}_{3}{ }_{2} \mathrm{PE}$ & SRNOM & $313 \pm 1$ & $17886 \pm 81$ & reduction \\
\hline $\begin{array}{c}\text { weathered } \\
\text { PE }\end{array}$ & SRNOM & $1212 \pm 21$ & $69257 \pm 1212$ & \\
\hline $\begin{array}{l}\text { weathered } \\
\mathrm{Fe}_{2} \mathrm{O}_{3} \mathrm{PE}\end{array}$ & SRNOM & $426 \pm 1$ & $24314 \pm 40$ & reduction \\
\hline
\end{tabular}

iron analysis of the leachates, the particle number concentrations indicate that releases originate from an iron contamination, not from the embedded pigments. Only in one leachate a significant increase in $\mathrm{Fe}$ particle number concentration was observed, while all other leachates showed a reduction of $\mathrm{Fe}$ particle number concentration or no significant change. Thus, we can conclude that nanoparticle-free PE releases Fe-containing nanoparticles, attributed to contaminations from handling, whereas the embedded $\mathrm{Fe}_{2} \mathrm{O}_{3}$ only entailed particulate release in DIW. We used this one case of increase to derive an upper limit of Fe particle release of 1600 particles/mL (difference in DIW between 1886 particles $/ \mathrm{mL}$ for $\mathrm{Fe}_{2} \mathrm{O}_{3} \mathrm{PE}$ and 286 particles/mL for $\mathrm{PE}$ ). The variability between leachates is on the same order. Converted to mass metrics, the upper limit is $0.4 \mathrm{ng} / \mathrm{L}$ corresponding to $6 \mathrm{ppb}$ of the initial amount present in the nanocomposite. With this, the particulate release is considerably lower compared to $\mathrm{Fe}$ released in ionic form.

Figure 8 summarizes the scenarios investigated here (highlighted in blue) among other possible scenarios, and also integrates rates and forms of release for both pigment case studies derived from the experimental results. Representative for the two considered applications of the nanopigments in car bumpers and food packaging, we investigated several primary and one secondary release scenario (where secondary means the synergy of first mechanical fragmentation, then environmental leaching). The chosen scenarios can be regarded representative for the use and end-of-life phase of the nanopigments' life cycle. Primary release of airborne fragments was studied independently. ${ }^{44}$

Morphological degradations of materials induced by the two weathering scenarios (scenario I and II) were only minor for OrgPig_PE and pure PE plates. In case of $\mathrm{Fe}_{2} \mathrm{O}_{3} \mathrm{PE}$ more 


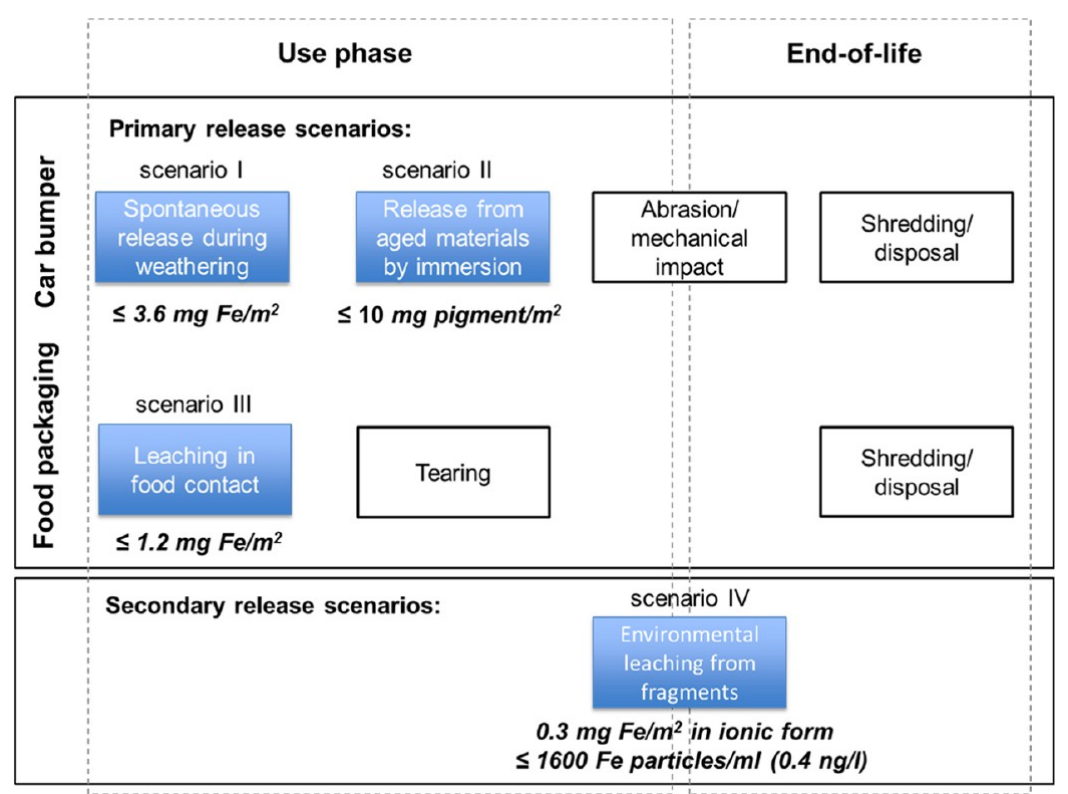

Figure 8. Summary of possible and investigated (highlighted in blue) release scenarios for both pigment case studies and of derived rates and forms of release during experimental analyses. Release was negligible against background within the experimental error for all investigated scenarios. Thus, all release rates are given as upper limits that might be enhanced by better specificity of the analysis techniques and by lower environmental backgrounds of the characteristic elemental compositions and of the characteristic size ranges. In all investigated scenarios, handling and machining of the plastics by standard processing equipment induced higher releases than the embedded nanopigments.

pronounced morphological changes, especially the formation of cracks, were observed. We assume cracking to be a result of PE matrix oxidation causing chain scission, secondary crystallization, and a densification of the material on the exposed surface, finally leading to cracking. The UV stabilizer proved to be effective to retain gloss and to limit photodegradation, but the presence of $\mathrm{Fe}_{2} \mathrm{O}_{3}$ significantly enhanced the oxidation of PE. To understand why cracking was only observed on the $\mathrm{Fe}_{2} \mathrm{O}_{3}$ PE nanocomposite, we have to consider two synergistic effects: on the one hand chain scission induced by photooxidation lowers the mechanical strength of the polymer composite while on the other hand secondary crystallization of short chains induces mechanical stress. When this mechanical stress overcomes the resistance of the material, cracking occurs. In our study this limit is only reached for $\mathrm{Fe}_{2} \mathrm{O}_{3} \mathrm{PE}$ possibly due to the amplification of photo-oxidation by the nanopigment itself. Cracking took place mostly around large $\mathrm{Fe}_{2} \mathrm{O}_{3}$ aggregates, as these represent a discontinuity in the material and with this a preferential site for strain release. In addition, it cannot be excluded that volatilization of LDPE (present in a multiple of the nanopigment concentration from the masterbatch that was used to compound the nanopigments into the HDPE) can contribute to crack formation by weakening the mechanical strength of the material and/or applying additional pressure on the polymer matrix when volatilization takes places below the surface.

Cracks increase the surface and might eventually facilitate release of the $\mathrm{Fe}_{2} \mathrm{O}_{3}$ nanopigment present in superficial layers. However, $\mathrm{Fe}$ release determined in runoff waters during weathering of nanocomposite plates in scenario I was low compared to equipment-induced Fe contaminations. An overall maximum release rate of $3.6 \mathrm{mg} \mathrm{Fe} / \mathrm{m}^{2}$ from the embedded $\mathrm{Fe}_{2} \mathrm{O}_{3}$ pigment was estimated as a worst case. This includes both free ionic and free particulate iron compounds, but excludes matrix-embedded iron. Scenario II, which investigated release after weathering by immersion and mechanical stress, resulted in a maximum release rate for both pigments of 10 $\mathrm{mg} / \mathrm{m}^{2}$ including both free and embedded pigments. This is several orders of magnitude below releases from epoxy at equal aging. ${ }^{39}$ No significant increase of release was observed in comparison to as-produced materials, in spite of the photooxidation of the polyethylene matrix observed for both composites. TEM observation revealed some free $\mathrm{Fe}$-containing aggregates, but they clearly differed from the initial $\mathrm{Fe}_{2} \mathrm{O}_{3}$ nanoparticles and we suggest that these were transformed from primary $\mathrm{Fe}$-ion release to $\mathrm{Fe}^{3+} \mathrm{OOH}$ through a couple of redox reactions, triggered by the photo-oxidation of polyethylene. ${ }^{41}$

Measurements of mass loss of the macroscopic specimen (plastic plate) during aging are sometimes interpreted as indirect evidence of release, ${ }^{45-47}$ however, taking all the evidence on scenarios I and II together, lost mass is not necessarily found in the form of released fragments. We attribute this mismatch to the loss of LDPE or other volatile species in case of the nanocomposite plates. Release in food contact (scenario III) also revealed a very low release of free and embedded $\mathrm{Fe}\left(\leq 0.0002 \%\right.$ of initial mass, $\left.\geq 1.2 \mathrm{mg} \mathrm{Fe} / \mathrm{m}^{2}\right)$ below the ICP-MS detection limit. In summary, release during all investigated primary release scenarios was negligible compared to background contaminations.

Environmental leaching, which was investigated representative for a secondary release scenario, resulted in a Fe release of $0.002 \%$ of the initial $\mathrm{Fe}$ mass $\left(0.3 \mathrm{mg} \mathrm{Fe} / \mathrm{m}^{2}\right)$. Analysis by spICP-MS showed that low but significant $\mathrm{Fe}$ release in particulate form occurred from any specimen, including the nanoparticle-free $\mathrm{PE}$, whereas embedded $\mathrm{Fe}_{2} \mathrm{O}_{3}$ induced no significant increase of particulate release except in DIW (in fact a reduction was observed in four of six cases). The one case of an increase of $1600 \mathrm{Fe}$ particles $/ \mathrm{mL}$, which corresponds to 0.4 $\mathrm{ng} / \mathrm{L}$ in the leachate or $6 \mathrm{ppb}$ of the initial amount present in the nanocomposite, can be estimated as an upper limit of $\mathrm{Fe}$ particle release, although it was not possible to identify that particulate release with the original nanopigment. No migration 
of particles within the matrix was observed which is in good agreement with the literature. ${ }^{449}$ The nanopigment particles degraded (if at all) ionically in the PE polymer matrix with a subsequent release in ionic form and subsequent transformation. Such a process was also described by Pillai et al. for semiconductor nanoparticles (quantum dots). ${ }^{49}$

The overall very low release from the HDPE matrix is expected from migration theory ${ }^{47,48}$ and from the known stability of HDPE against hydrolysis and photolysis. ${ }^{37}$ The low release is further put into perspective by a comparison of release from the same nanomaterials from different matrices, confirming that the resilience of the matrix is the most critical factor in weathering release. ${ }^{39}$ Finally, the present laboratory simulation of PE weathering by up to 12 weeks using ISO protocol 4892-2A represents real-world aging of durations between 1.8 and 6.9 years depending on the outdoor climate. This extrapolation is based on an extensive comparison of carbonyl indices (as given also in Figure 5 for direct comparison) between ISO4892 and several outdoor weathering locations at different climates on polypropylene (PP) as closely related polyolefin matrix. ${ }^{36}$ The present results cannot be generalized to less resilient polymer matrices, but they confirm the safer-by-design advice that lifecycle release of nanomaterials can be effectively controlled by the choice of a polymer matrix that is resilient under the anticipated lifecycle scenarios.

\section{ASSOCIATED CONTENT}

\section{S Supporting Information}

The Supporting Information is available free of charge on the ACS Publications website at DOI: 10.1021/acs.est.7b02578.

Intrinsic and extrinsic physical-chemical properties of the nanopigments and nanocomposite; production process of fragmented products; detailed methods for aging, sampling and analysis of aged matrix and released fragments; results surface morphology (SEM) and chemical degradation (FTIR) of nanocomposites and controls; results on releases (AUC quantification, TEM image analysis, single-particle-ICPMS quantification of ionic and particulate leaching) (PDF)

Movie from X-ray computed microtomography (DOCX)

\section{AUTHOR INFORMATION}

\section{Corresponding Author}

*Phone: 0049621 6095339; e-mail: wendel.wohlleben@basf. com.

\section{ORCID}

Wendel Wohlleben: 0000-0003-2094-3260

\section{Present Address}

${ }^{\perp}$ U.S. National Research Council Associate, Environmental Protection Agency, Research Triangle Park, North Carolina 27709, United States.

\section{Notes}

The authors declare the following competing financial interest(s): NN and WW are employees of BASF, a company producing and marketing nanomaterials.

\section{ACKNOWLEDGMENTS}

We gratefully acknowledge the excellent laboratory support by Klaus Vilsmeier at BASF SE. This work was supported by the project on Sustainable Nanotechnologies (SUN) that receives funding from the European Union Seventh Framework
Programme (FP7/2007-2013) under grant agreement no. 604305. The French X-ray Computed Tomography platform called Nano-ID was funded by the EQUIPEX project ANR-10EQPX-39-01.

\section{REFERENCES}

(1) Froggett, S.; Clancy, S.; Boverhof, D.; Canady, R. A review and perspective of existing research on the release of nanomaterials from solid nanocomposites. Part. Fibre Toxicol. 2014, 11 (1), 17.

(2) Schlagenhauf, L.; Nüesch, F.; Wang, J. Release of Carbon Nanotubes from Polymer Nanocomposites. Fibers 2014, 2 (2), 108.

(3) Harper, S.; Wohlleben, W.; Doa, M.; Nowack, B.; Clancy, S.; Canady, R; Maynard, A. Measuring Nanomaterial Release from Carbon Nanotube Composites: Review of the State of the Science. J. Phys.: Conf. Ser. 2015, 617 (1), 012026.

(4) Duncan, T. V. Release of Engineered Nanomaterials from Polymer Nanocomposites: the Effects of Matrix Degradation. ACS Appl. Mater. Interfaces 2014, 7, 20-39.

(5) Nowack, B.; David, R. M.; Fissan, H.; Morris, H.; Shatkin, J. A.; Stintz, M.; Zepp, R.; Brouwer, D. Potential release scenarios for carbon nanotubes used in composites. Environ. Int. 2013, 59, 1-11.

(6) Kingston, C.; Zepp, R.; Andrady, A.; Boverhof, D.; Fehir, R.; Hawkins, D.; Roberts, J.; Sayre, P.; Shelton, B.; Sultan, Y.; Vejins, V.; Wohlleben, W. Release Characteristics of Selected Carbon Nanotube Polymer Composites. Carbon 2014, 68, 33-57.

(7) Shandilya, N.; Bihan, O. L.; Morgeneyer, M. A review on the study of the generation of (nano)particles aerosols during the mechanical solicitation of materials. J. Nanomater. 2014, 2014, 5-5.

(8) Shandilya, N.; Le Bihan, O.; Morgeneyer, M. Effect of the Normal Load on the Release of Aerosol Wear Particles During Abrasion. Tribol. Lett. 2014, 55 (2), 227-234.

(9) Shandilya, N.; Le Bihan, O.; Bressot, C.; Morgeneyer, M. Emission of Titanium Dioxide Nanoparticles from Building Materials to the Environment by Wear and Weather. Environ. Sci. Technol. 2015, 49 (4), 2163-2170.

(10) Fiorentino, B.; Golanski, L.; Guiot, A.; Damlencourt, J.-F.; Boutry, D. Influence of paints formulations on nanoparticles release during their life cycle. J. Nanopart. Res. 2015, 17 (3), 149.

(11) Nguyen, T.; Pellegrin, B.; Bernard, C.; Gu, X.; Gorham, J.; Stutzman, P.; Stanley, D.; Shapiro, A.; Byrd, E.; Hettenhouser, R.; Chin, J. Fate of nanoparticles during life cycle of polymer nanocomposites. J. Phys: Conf Ser. 2011, 304, 012060.

(12) Hirth, S.; Cena, L. G.; Cox, G.; Tomovic, Z.; Peters, T. M.; Wohlleben, W. Scenarios and methods that induce protruding or released CNTs after degradation of composite materials. J. Nanopart. Res. 2013, 15, 1504.

(13) Wohlleben, W.; Meier, M. W.; Vogel, S.; Landsiedel, R.; Cox, G.; Hirth, S.; Tomović, Ž. Elastic CNT-polyurethane nanocomposite: synthesis, performance and assessment of fragments released during use. Nanoscale 2013, 5 (1), 369-380.

(14) Wohlleben, W.; Brill, S.; Meier, M.; Mertler, M.; Cox, G.; Hirth, S.; von Vacano, B.; Strauss, V.; Treumann, S.; Wiench, K.; Ma-Hock, L.; Landsiedel, R. On the lifecycle of nanocomposites: comparing released fragments and their in-vivo hazards from three release mechanisms and four nanocomposites. Small 2011, 7, 2384-2395.

(15) Saber, A. T.; Mortensen, A.; Szarek, J.; Koponen, I. K.; Levin, M.; Jacobsen, N. R.; Pozzebon, M. E.; Mucelli, S. P.; Rickerby, D. G.; Kling, K.; Atluri, R.; Madsen, A. M.; Jackson, P.; Kyjovska, Z. O.; Vogel, U.; Jensen, K. A.; Wallin, H. Epoxy composite dusts with and without carbon nanotubes cause similar pulmonary responses, but differences in liver histology in mice following pulmonary deposition. Part. Fibre Toxicol. 2015, 13 (1), 1-20.

(16) Saber, A.; Koponen, I.; Jensen, K.; Jacobsen, N.; Mikkelsen, L.; M?ller, P.; Loft, S.; Vogel, U.; Wallin, H. Inflammatory and genotoxic effects of sanding dust generated from nanoparticle-containing paints and lacquers. Nanotoxicology 2012, 6, 776-788.

(17) Saber, A. T.; Jensen, K. A.; Jacobsen, N. R.; Birkedal, R.; Mikkelsen, L.; M?ller, P.; Loft, S.; Wallin, H.; Vogel, U. Inflammatory 
and genotoxic effects of nanoparticles designed for inclusion in paints and lacquers. Nanotoxicology 2012, 6, 776-788.

(18) Pfaff, G. Inorganic Pigments, 2017.

(19) Buxbaum, G.; Pfaff, G. Industrial Inorganic Pigments. Wiley: 2006

(20) Herbst, W.; Hunger, K. Industrial Organic Pigments: Production, Properties, Applications, 3rd, Completely Revised ed.; Wiley, 2006; p 678.

(21) Stark, W.; Stoessel, P.; Wohlleben, W.; Hafner, A. Industrial applications of nanoparticles. Chem. Soc. Rev. 2015, 44 (16), 57935805.

(22) Ministère de l'Environnement. Éléments issus des déclarations des substances à l'état nanoparticulaire: Exercice 2015. 2015.

(23) Nowack, B.; Boldrin, A.; Caballero, A.; Hansen, S. F.; Gottschalk, F.; Heggelund, L.; Hennig, M.; Mackevica, A.; Maes, H.; Navratilova, J. Meeting the Needs for Released Nanomaterials Required for Further Testing- The SUN Approach. Environ. Sci. Technol. 2016, 50 (6), 2747-2753.

(24) Holmgren, G. G. S. A Rapid Citrate-Dithionite Extractable Iron Procedure1. Soil Science Society of America Journal 1967, 31 (2), 210211.

(25) Koivisto, A. J.; Jensen, A. C. Ø.; Kling, K. I.; Nørgaard, A.; Brinch, A.; Christensen, F.; Jensen, K. A. Quantitative material releases from products and articles containing manufactured nanomaterials: Towards a release library. NanoImpact 2017, 5, 119.

(26) Wohlleben, W.; Kingston, C.; Carter, J.; Sahle-Demessie, E.; Vázquez-Campos, S.; Acrey, B.; Chen, C.-Y.; Walton, E.; Egenolf, H.; Müller, P.; Zepp, R. NanoRelease: Pilot interlaboratory comparison of a weathering protocol applied to resilient and labile polymers with and without embedded carbon nanotubes. Carbon 2017, 113, 346-360.

(27) Nguyen, T. L.; Pellegrin, B.; Bernard, C.; Gu, X.; Gorham, J. M.; Stutzman, P.; Stanley, D.; Shapiro, A.; Byrd, E.; Hettenhouser, R.; Chin, J. Fate of nanoparticles during life cycle of polymer nanocomposites. J.Physics: Conf.Series 2011, 304 (1), 012060.

(28) Fernández-Rosas, E.; Vilar, G.; Janer, G.; González-Gálvez, D.; Puntes, V.; Jamier, V.; Aubouy, L.; Vázquez-Campos, S. Influence of Nanomaterial Compatibilization Strategies on Polyamide Nanocomposites Properties and Nanomaterial Release during the Use Phase. Environ. Sci. Technol. 2016, 50 (5), 2584-2594.

(29) Gulmine, J. V.; Janissek, P. R.; Heise, H. M.; Akcelrud, L. Degradation profile of polyethylene after artificial accelerated weathering. Polym. Degrad. Stab. 2003, 79 (3), 385-397.

(30) Craig, I. H.; White, J. R.; Kin, P. C. Crystallization and chemicrystallization of recycled photo-degraded polypropylene. Polymer 2005, 46 (2), 505-512.

(31) Chacko, V. P.; Karasz, F. E.; Farris, R. J.; Thomas, E. L. Morphology of CaCO3-filled polyethylenes. J. Polym. Sci., Polym. Phys. Ed. 1982, 20 (12), 2177-2195.

(32) Valadez-González, A.; Veleva, L. Mineral filler influence on the photo-oxidation mechanism degradation of high density polyethylene. Part II: natural exposure test. Polym. Degrad. Stab. 2004, 83 (1), 139148.

(33) Yang, R.; Liu, Y.; Yu, J.; Zhang, D. Spatial heterogeneity of photo-oxidation and its relation with crack propagation in polyethylene composites. Polym. Eng. Sci. 2008, 48 (11), 2270-2276.

(34) Nguyen, T.; Wohlleben, W.; Sung, L., Mechanisms of Aging and Release from Weathered Nanocomposites. In Safety of Nanomaterials along Their Lifecycle: Release, Exposure, and Human Hazards; Wohlleben, W., Kuhlbusch, T., Schnekenburger, J., Lehr, C. M., Eds.; CRC Press, 2014; pp 315-334.

(35) Ging, J.; Tejerina-Anton, R.; Ramakrishnan, G.; Nielsen, M.; Murphy, K.; Gorham, J. M.; Nguyen, T.; Orlov, A. Development of a conceptual framework for evaluation of nanomaterials release from nanocomposites: Environmental and toxicological implications. Sci. Total Environ. 2014, 473, 9-19.

(36) Lv, Y.; Huang, Y.; Yang, J.; Kong, M.; Yang, H.; Zhao, J.; Li, G. Outdoor and accelerated laboratory weathering of polypropylene: A comparison and correlation study. Polym. Degrad. Stab. 2015, 112, 145-159.
(37) Ammala, A.; Bateman, S.; Dean, K.; Petinakis, E.; Sangwan, P.; Wong, S.; Yuan, Q.; Yu, L.; Patrick, C.; Leong, K. H. An overview of degradable and biodegradable polyolefins. Prog. Polym. Sci. 2011, 36 (8), 1015-1049.

(38) Zerbi, G.; Gallino, G.; Del Fanti, N.; Baini, L. Structural depth profiling in polyethylene films by multiple internal reflection infra-red spectroscopy. Polymer 1989, 30 (12), 2324-2327.

(39) Wohlleben, W.; Neubauer, N. Quantitative rates of release from weathered nanocomposites are determined across 5 orders of magnitude by the matrix, modulated by the embedded nanomaterial. NanoImpact 2016, 1, 39-45.

(40) Auffan, M.; Achouak, W.; Rose, J.; Roncato, M.-A.; Chanéac, C.; Waite, D. T.; Masion, A.; Woicik, J. C.; Wiesner, M. R.; Bottero, J.-Y. Relation between the Redox State of Iron-Based Nanoparticles and Their Cytotoxicity toward Escherichia coli. Environ. Sci. Technol. 2008, 42 (17), 6730-6735.

(41) Waite, T. D.; Morel, F. M. M. Photoreductive dissolution of colloidal iron oxides in natural waters. Environ. Sci. Technol. 1984, 18 (11), 860-868.

(42) Lee, S.; Bi, X.; Reed, R. B.; Ranville, J. F.; Herckes, P.; Westerhoff, P. Nanoparticle Size Detection Limits by Single Particle ICP-MS for 40 Elements. Environ. Sci. Technol. 2014, 48 (17), 1029110300.

(43) Tuoriniemi, J.; Cornelis, G.; Hassellöv, M. Size Discrimination and Detection Capabilities of Single-Particle ICPMS for Environmental Analysis of Silver Nanoparticles. Anal. Chem. 2012, 84 (9), 3965-3972.

(44) Koivisto, A. J.; Kling, K. I.; Levin, M.; Fransman, W.; Gosens, I.; Cassee, F. R.; Jensen, K. A. First order risk assessment for nanoparticle inhalation exposure during injection molding of polypropylene composites and production of tungsten-carbide-cobalt fine powder based upon pulmonary inflammation and surface area dose. NanoImpact 2017, 6, 30-38.

(45) Jacobs, D. S.; Huang, S.-R.; Cheng, Y.-L.; Rabb, S. A.; Gorham, J. M.; Krommenhoek, P. J.; Yu, L. L.; Nguyen, T.; Sung, L. Surface degradation and nanoparticle release of a commercial nanosilica/ polyurethane coating under UV exposure. J. Coat. Technol. Res. 2016, 13 (5), 735-751.

(46) Sung, L.; Stanley, D.; Gorham, J. M.; Rabb, S.; Gu, X.; Yu, L. L.; Nguyen, T. A quantitative study of nanoparticle release from nanocoatings exposed to UV radiation. J. Coat. Technol. Res. 2015, $12,121-135$.

(47) Duncan, T. V.; Pillai, K. Release of Engineered Nanomaterials from Polymer Nanocomposites: Diffusion, Dissolution, and Desorption. ACS Appl. Mater. Interfaces 2014, 7, 1-19.

(48) Störmer, A.; Bott, J.; Kemmer, D.; Franz, R. Critical review of the migration potential of nanoparticles in food contact plastics. Trends Food Sci. Technol. 2017, 63, 39-50.

(49) Pillai, K. V.; Gray, P. J.; Tien, C.-C.; Bleher, R.; Sung, L.-P.; Duncan, T. V. Environmental release of core-shell semiconductor nanocrystals from free-standing polymer nanocomposite films. Environ. Sci.: Nano 2016, 3, 657. 